\title{
Effects of the Older Family Network Program on Improving Quality of Life Among Older Adults in Thailand
}

\author{
Korravarn Yodmai' \\ Ratana Somrongthong ${ }^{2}$ \\ Sutham Nanthamongkolchai $\left(\mathbb{D}^{1}\right.$ \\ Wanich Suksatan (iD) ${ }^{3}$ \\ 'Faculty of Public Health, Mahidol \\ University, Bangkok, Thailand; ${ }^{2}$ College of \\ Public Health Science, Chulalongkorn \\ University, Bangkok, Thailand; ${ }^{3}$ Faculty of \\ Nursing, HRH Princess Chulabhorn \\ College of Medical Science, Chulabhorn \\ Royal Academy, Bangkok, Thailand
}

Correspondence: Wanich Suksatan Faculty of Nursing, HRH Princess Chulabhorn College of Medical Science, Chulabhorn Royal Academy, Bangkok, Thailand

Tel +668-27550027

Email wanich.suk@pccms.ac.th
Background: The evidence of promoting family members' health care for older adults by applying family networks and theory of planned behavior will lead to mental health and lower the quality of life among older adults in rural community in Thailand is unclear.

Objective: The study aimed to assess the effects of health promotion among older adults using an aging family network program to reduce depression and improve quality of life (QOL) among older adults.

Patients and Methods: This quasi-experimental study was enrolled on one hundred and ten older adults and their family members. Fifty-five older adult participants joined the health promoting program using family member involvement. This program trained them to change health behaviors such as eating healthy food, exercising, emotion management and disability preventive activities to reduce dementia, stroke and falls. The program was conducted in a rural community for 12 months. A comparison group program conducted usual health promoting activities by health personnel. They evaluated quality of life (QOL) using WHOQOL-OLD measurement, and 30-item geriatric depression scale before implementing interventions and after interventions at 9th and 12th months. Data were analyzed using general linear mixed model analysis.

Results: After the intervention, social support and perception of health care from family members were significantly improved at the 9th month. At the 12th month, overall QOL, sensory ability, social participation, intimacy, social support, and perception of health care from family members significantly improved. Depression was also reduced at the 12 th month. Conclusion: These findings demonstrated that health promotion using family members improved QOL and reduced depression long term. Policymakers should implement programs to improve QOL among older adults. They need to improve the involvement of family members when conducting health promotion among older adults and support funding due to conduct on weekends or in the evening.

Keywords: family role, quality of life, older adult, rural community

\section{Introduction}

Older individuals living with chronic diseases are often paradoxically observed to have a higher risk of dependency than individuals who are disease-free. ${ }^{1}$ Most studies have used many theoretical changes to promote health; however, one single theory has several limitations such as less motivated to change when residing at home or unable to change due to family members' lifestyle. As is well known, some healthy behaviors, eg, consumption and exercise, are related to family lifestyle. ${ }^{2,3}$ For 
example, when a family member eats sweet food, other family members will also consume because they eat together. Thus, separating the food from patients or those who are healthy cannot be done. Many studies have promoted the health of the elderly without family member participation. Family members play a large role in social support for older adults, such as preparing food and maintaining a safe environment in the home. ${ }^{4,5}$ However, few studies have applied the role of family members to support changes in health behaviors to improve the quality of life (QOL) among older adults. ${ }^{6,7}$

Related studies have demonstrated that family support exhibits a relationship with health behaviors of older adults and their QOL. ${ }^{8,9}$ In a study of Crimmins, Zhang ${ }^{10}$ demonstrated that the family support increased life expectancy among older adults. Various studies have shown that selfcare behaviors can significantly diminish the number of hospitalizations, ${ }^{11}$ mortality rate, ${ }^{10}$ and care cost burdens. $^{12,13}$ Among older adults with chronical illness, administering self-care is difficult as a result of complicated medical diets, the nature of the disease, as well as complications in various physical functions resulting in poor selfcare. ${ }^{14,15}$ Therefore, providing efficient support for self-care among older adults is essential and important. ${ }^{16}$

Family members are an important source of social support closely associated with self-care activities. ${ }^{3}$ Participation and support of family members at home can play a key role in self-care behaviors and efficiency of disease control. ${ }^{7}$ Shahriari et $\mathrm{al}^{17}$ demonstrated that family can influence the success and stability of behavior change in self-care programs. Moreover, several studies have revealed that family support influences self-care behaviors such as restricting regular medication, exercise, and referrals to physicians in the case of observed abnormal conditions. ${ }^{17}$ More family support for patients greatly affects behavioral change and health outcomes. Moreover, the elderly family members often have no knowledge about disease, its signs and treatment and elderly care, especially how they could support and encourage the elderly to follow self-care behaviors. ${ }^{2}$ Related studies have indicated that taking care of the elderly also affected stress and fatigue levels among family members resulting in being uninterested in joining health promoting activities with the elderly. ${ }^{18}$ For this reason, motivating family members to be interested and involved in promoting elderly health and participating in health promoting activities for older adults are important.
The theory of planned behavior links an individuals' behavior and their beliefs regarding attitudes, subject norms and perceived behavioral control. ${ }^{19}$ Those beliefs lead to intention to change behavior and act out the behavior. ${ }^{19}$ This theory was extended from the theory of reasoned action in $1980 .{ }^{20}$ This theory has been used successfully to predict and explain health behaviors including smoking, alcohol consumption, health services use, breastfeeding practices and substance use. ${ }^{21}$ Behavioral achievement depends on motivation (intention) and ability (behavioral control). Behavioral intention is changed by attitude toward the behavior, their peers or important individuals in society concerning those behaviors, and an individual's ability to act out the behavior.

Previous studies have examined health promotion interventions by family participation and focused on older adults' individual self-care knowledge and behaviors. $^{22,23}$ Despite evidence proving the important role of family support and theory of planned behavior in self-care, health promotion among family members, and quality of life (QOL) among older adults have been less investigated, particularly in Thailand. To the best of our knowledge, there remains unclear evidence promoting family members' health care for older adults by applying family networks and theory of planned behavior will lead to depression and lower the QOL among older adults. Therefore, the present study aimed to assess the effects of elderly family network intervention on improving the QOL and to reduce depression among older adults.

\section{Patients and Methods}

\section{Research Design and Sampling}

This quasi-experimental study was part of an aging family network program conducted from 2017 to 2018. This paper aimed to present the impact of an aging family network program applying the social network concept and theory of planned behavior to encourage family members of older adults to provide health care in their homes and participate in health promoting activities with their older adults.

The sample size was calculated by using the $G *$ power program to be 55 older adults with chronic diseases, including hypertension, diabetes, hyperlipidemia, and heart diseases in each study and comparison group. A total of 110 participants were selected using the criteria; 1) aged 60 to 80 years and 2) living with family members aged 20 to 59 years who were literate. Older adults who had a history of psychiatric disorders and unable to speak and read the official 
language of Thailand were excluded from this study. The study areas were selected by convenient sampling, and then participants were randomly selected in each group from name lists of primary health promoting centers (subdistrict health promoting hospitals). Study areas were located in Som-Sung District (intervention group) and Num-Phong District (comparison group), Khon Kaen Province, Thailand.

\section{Intervention}

After the Institutional Review Board (IRB) approval, we met with participants and explained the study objective and procedures, including sample rights protection. Signed informed consent was obtained from all participants willing to participate.

In the intervention group, participants were randomly assigned, asked to attend the older adult health care training for four sessions and to join monthly activities for 9 months. Then, participants were separated in groups. Each group selected a group leader and trained to be a team leader for two sessions. The older adult health care training comprised four sessions. The first session covered basic health issues for older adults, and the second covered how to promote healthy food consumption. The third comprised how to promote physical activities among older adults, and the fourth consisted of how to prevent emotional burden among older adults. The training was conducted at a community health center and two hours was spent in each session. Before starting the new session, trainers reviewed previous knowledge for about 30 minutes. Trainers included nurses, nutritionist, and physiotherapist. After training, family members joined the monthly meeting with their seniors for 12 months. The training activities related to exercise, food and beverage selection, dementia prevention activities, emotional management, diabetes, hypertension and hyperlipidemia care in the home and meditation. The control group received usual care or routine practices provided by health professionals at their community health center.

\section{Research Instrument}

The questionnaire contained six sections, consisted of demographic characteristics, perception of health care from family caregiver, family member support, family relationships, depression, and QOL.

\section{Perception of Health Care (PHC)}

In the present research, we developed the PHC based on the literature review, which was assessed using ten items ranked on a five-response Likert scale (from one $=$ never to five $=$ always). Total scores ranged from 10 to 50 points. Individuals scoring 10 to 30 were assigned "low", 31 to 40 "moderate", and 41 to 50 "high" family supports. The instrument and contents of PHC were reviewed and validated by a panel of five content experts consisting of a family physician, a gerontological nurse practitioner, a physiotherapist, and a nurse researcher. The scale was reliable, exhibiting a Cronbach's alpha of 0.85 .

\section{Family Support}

Family support was developed by the researchers based on the literature review and concept of social support, ${ }^{24}$ which was assessed using ten items ranked on a fiveresponse Likert scale (from one $=$ never to five $=$ always). Total scores ranged from 10 to 50 points. Individuals scoring 10 to 30 were assigned "low", 31 to 40 "moderate", and 41 to 50 "high" family supports. The scale was reliable, exhibiting a Cronbach's alpha of 0.85 .

\section{Family Relationship}

The researchers created the Family Relationship scale based on the literature review, which was assessed using 12 items with a five-response Likert scale. Total family relationship scores ranged from 12 to 60 were divided into three levels: 12 to 36 , low family relationship; 37 to 48 , moderate family relationship and 49 to 60 , high family relationship. In the current study, the tool and contents of Family Relationship Scale were reviewed and validated by a panel of five content experts consisting of a family physician, a gerontological nurse practitioner, a physiotherapist, and a nurse researcher with a Cronbach's alpha of 0.78 .

\section{Depression}

The 30-item geriatric depression scale (GDS) was developed by Yesavage et al, ${ }^{25}$ and translated in Thai version by Brain Rehabilitation Group ${ }^{26}$ to measure depression. The answers were "yes" and "no" (yes = 1 and no $=0$ ). Seven negative items were reversed scored. The score ranged from 0 to 30 points. Scores 0 to 12 were assigned to no depression, 13 to 19 to mild depression, and 19 to 30 to severe depression. The scale was reliable with a Cronbach's alpha of 0.85 .

\section{Quality of Life (QOL)}

The WHOQOL-OLD measurement developed by Power et $\mathrm{al}^{27}$ and translated into Thai version by Somrongthong et al, ${ }^{28}$ to measure QOL in older adults. It consisted of six facets of 24 items. Responses used a fivepoint Likert scale (from $0=$ less to five $=$ very high). Based on 
this scale, the obtained scores ranged from 24 to 120 points. Scores of 24 to 58 were assigned to "poor", 58 to 98 to "moderate", and 99 to 120 to "good" QOL. Each facet contained four items covering six facets (sensory ability (SAB)), autonomy (AUT), social participation (SOP), physical function or past-present-future activity (PPF), death and dying (DAD), and intimacy (INT). In each facet, the score ranged from 4 to 20. The scale ranges comprised 4 to 12 , low QOL level; 12 to 16, moderate QOL level and 16 to 20, high QOL. The scale was reliable, with a Cronbach's alpha of 0.085 .

\section{Sociodemographic Variables}

Socioeconomic characteristics consisted of nine items with multiple choices and open-ended questions. We developed this tool based on literature reviews, including age, education levels, marital status, income sufficiency, major source of income, career when sick, general supporter, consultant during emotional problem, and satisfaction with caring by family members.

\section{Ethical Considerations}

This research study was approved by the Ethical Review Committee for Human Research of Faculty of Public Health, Mahidol University (Research Project Code No. MUPH 2017-139), dated June 20, 2017. This study was conducted in accordance with the Declaration of Helsinki.

\section{Statistical Analysis}

Data were analyzed using the Statistical Package for the Social Sciences (SPSS), Version 21 for Windows (SPSS, Chicago, IL) for testing the assumptions, study variables, and outcomes. Characteristics of the participants were described using descriptive statistics, including frequency (percentage) or mean \pm standard deviation. Student's $t$-test, chi-square, Fisher's exact test, and repeated measure ANOVA analysis were performed to determine the associations between QOLs at different times. The assumptions of Student's $t$-test and ANOVA showed no violations of normality and homogeneity of variance. The main objective of our study is to explore whether the improvement of those outcomes before and after the older family network program differs between intervention and control groups. The effects of the intervention at follow-ups I and II were tested using linear mixed models (LMM) with unadjusted values. The use of LMM for analyzing repeated-measure data results in a more precise parameter estimation than that in traditional statistical methods (eg, linear regression). ${ }^{29,30}$ A p-value $<0.05$ was considered statistically significant.

\section{Results}

\section{Characteristics of the Study Population}

Regarding family careers, the average length was 45 years $(\mathrm{SD} \pm 7.17)$ in the intervention group and 43 years (SD \pm 8.38 ) in the comparison group, without significant difference. Most respondents had obtained primary school education level (63.6\% in the intervention group and $49.1 \%$ in the comparison group), were married (78.2\% in the intervention group and $56.4 \%$ in comparison group), farmers (67.4\% in the intervention group and $63.4 \%$ in the comparison group) and received sufficient income (50.9\% in the intervention group and $83.6 \%$ in the comparison group). No statistically difference was found between groups regarding education and occupation. However, marital status and sufficient income differed significantly (Table 1).

Among older adults, most of the participants were female, $78.18 \%(n=43)$, average age was 68 years (SD $\pm 5.913)$ in the intervention group and $74.55 \%(n=41)$ were female, average age was 69 years in the comparison group ( $\mathrm{SD} \pm 5.932$ ), without significant difference. Most respondents were educated in primary school $(65.5 \%$ of the intervention group and $69.1 \%$ of the comparison group), were married $(49.1 \%$ of the intervention group and $54.5 \%$ of the comparison group), received sufficient income $(52.7 \%$ of the intervention group and $47.3 \%$ of the comparison group), were sick and cared for by a grandchild (41.8\% of the intervention group and $49.1 \%$ of the comparison group), received general care by a grandchild $(50.9 \%$ of the intervention group and $49.1 \%$ of the comparison group), received emotional counseling by a daughter (43.6\% of the intervention group and $38.2 \%$ of the comparison group), and received strong satisfaction from the care by family members (47.3\% of the intervention group and $52.7 \%$ of the comparison group). However, the majority of older adults reported moderate health $(60 \%$ of the intervention group and $67.3 \%$ of the comparison group), vision impairment $(61.8 \%$ of the intervention group and $54.5 \%$ of the comparison group and had reported falls (78.2\% of the intervention and $76.4 \%$ of the comparison group) (Table 1). 
Table I Socio-Demographic Characteristics

\begin{tabular}{|c|c|c|c|}
\hline Variable & Intervention Group n (\%) & Comparison Group n (\%) & p-value \\
\hline Age (years) (Mean $\pm S D)$ & $68.13 \pm 5.913$ & $68.76 \pm 5.932$ & $0.630^{\mathrm{a}}$ \\
\hline \multicolumn{4}{|l|}{ Gender } \\
\hline Female & $43(78.18 \%)$ & $4 \mid(74.55 \%)$ & $0.823^{\mathrm{a}}$ \\
\hline Male & $12(21.82 \%)$ & 14 (25.45\%) & \\
\hline \multicolumn{4}{|l|}{ Education } \\
\hline Primary school & $36(65.5 \%)$ & $38(69.1 \%)$ & $0.684^{\mathrm{a}}$ \\
\hline Secondary school and higher & 19 (34.5\%) & $17(32.7 \%)$ & \\
\hline \multicolumn{4}{|l|}{ Marital status } \\
\hline Single & $10(18.2 \%)$ & $7(12.7 \%)$ & $0.709^{\mathrm{a}}$ \\
\hline Married & 27 (49.1\%) & $30(54.5 \%)$ & \\
\hline Divorced/Widowed & $18(32.7 \%)$ & $18(32.7 \%)$ & \\
\hline \multicolumn{4}{|l|}{ Income sufficiency } \\
\hline Sufficient \& saving & $10(18.2 \%)$ & 5 (9.1\%) & $0.587^{\mathrm{a}}$ \\
\hline Sufficient without saving & $19(34.5 \%)$ & $21(38.2 \%)$ & \\
\hline Insufficient & $8(14.5 \%)$ & $9(16.4 \%)$ & \\
\hline Insufficient and poverty & $18(32.7 \%)$ & $20(36.4 \%)$ & \\
\hline \multicolumn{4}{|l|}{ Major source of income } \\
\hline Couple & $5(9.1 \%)$ & $6(10.9 \%)$ & $0.947^{\mathrm{a}}$ \\
\hline Son & $10(18.2 \%)$ & II (20.0\%) & \\
\hline Daughter & $16(29.1 \%)$ & 17 (30.9\%) & \\
\hline Pension & $24(43.6 \%)$ & $21(38.2 \%)$ & \\
\hline \multicolumn{4}{|l|}{ Career when sick } \\
\hline Couple & II (20.0\%) & $15(27.3)$ & $0.333^{\mathrm{a}}$ \\
\hline Son & II (20.0\%) & $5(9.1 \%)$ & \\
\hline Daughter & $23(4 I .8 \%)$ & $27(49.1 \%)$ & \\
\hline Other such as grandchild, relative & $10(18.2 \%)$ & $8(14.5 \%)$ & \\
\hline \multicolumn{4}{|l|}{ General supporter } \\
\hline Couple & $15(27.3 \%)$ & $12(21.8 \%)$ & $0.808^{\mathrm{a}}$ \\
\hline Son & 7 (I2.7\%) & $10(18.2 \%)$ & \\
\hline Daughter & $28(50.9 \%)$ & $27(49.1 \%)$ & \\
\hline Other such as grandchild, relative & $5(9.1 \%)$ & $6(10.9 \%)$ & \\
\hline \multicolumn{4}{|c|}{ Consultant during emotional problem } \\
\hline Couple & $12(21.8 \%)$ & II (20.0\%) & $0.870^{\mathrm{b}}$ \\
\hline Son & $15(27.3 \%)$ & $19(34.5 \%)$ & \\
\hline Daughter & $24(43.6 \%)$ & $21(38.2 \%)$ & \\
\hline Other such as grandchild, relative & $4(7.3 \%)$ & $4(7.3 \%)$ & \\
\hline \multicolumn{4}{|c|}{ Satisfaction with caring by family member } \\
\hline Good & $26(47.3 \%)$ & $29(52.7 \%)$ & $0.492^{\mathrm{a}}$ \\
\hline Fair & 17 (30.9\%) & $20(36.4 \%)$ & \\
\hline Poor & $12(21.8)$ & $6(14.5 \%)$ & \\
\hline
\end{tabular}

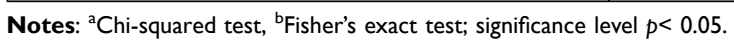

\section{Outcome Variables at Baseline}

Among older adults, most reported moderate quality of life (83.6\% of the intervention group and $85.5 \%$ of the comparison group), without significant difference. When classifying QOL in six facets, most had moderate level in sensory ability $(52.7$ and $60 \%$ of the intervention and comparison groups, respectively), autonomy (80 and $87 \%$ of the intervention and comparison groups, respectively), 
social support (74.5 and $80 \%$ of the intervention and comparison groups, respectively), physical ability (76.4 and $78.2 \%$ of the intervention and comparison groups, respectively), death and dying (50.9\% of the intervention and comparison groups, respectively) and intimacy (60 and $63.5 \%$ of the intervention and comparison groups, respectively). After comparing between intervention and comparison groups using the independent $t$-test, most facets did not differ significantly ( $p$-value $>0.05$ ), except social participation facet.

Surprisingly, over $60 \%$ of respondents had depression. Regarding depression, most reported mild depression (87.9 and $89.5 \%$ of the intervention and comparison groups, respectively). The majority reported low perception level of health care by family member $(67.3$ and $54.5 \%$ of the intervention and comparison groups, respectively), moderate family relationship ( $70.9 \%$ and $76.4 \%$ of the intervention and comparison groups, respectively), and moderate social support (63.6 and $52.7 \%$ of the intervention and comparison groups, respectively).

\section{Effects of Intervention Among Difference} Times

After implementing, the results showed that overall QOL value in the intervention group was $81.65 \pm 9.35$ at first follow-up and $85.62 \pm 7.66$ at second follow-up $(p<0.001)$ while in the comparison group values were $77.57 \pm 12.11$ and $76.13 \pm 9.18(p=0.330)$, respectively. In each facet, sensory ability values in the intervention group were 12.38 \pm 4.80 and $12.67 \pm 3.07(p=0.448)$, and in the comparison group values were $11.20 \pm 2.97$ and $11.33 \pm 2.84(p=$ 0.895), respectively. Autonomy values in the intervention group were $13.47 \pm 2.16$ and $13.89 \pm 2.00(p=0.151)$, and in the comparison group values were $12.78 \pm 2.04$ and $12.87 \pm 2.16(p=0.958)$, respectively. PPF values in the intervention group were $13.49 \pm 2.32$ and $14.25 \pm 2.00(p<$ $0.001)$ while in the comparison group values were $13.22 \pm$ 2.18 and $12.78 \pm 2.18(p=0.308)$, respectively. SOP values were $13.80 \pm 2.05$ and $14.56 \pm 1.87(p=0.003)$, and in the comparison group values were $12.70 \pm 2.30$ and $12.95 \pm 2.47(p=0.184)$, respectively. DAD values in the intervention group were $13.49 \pm 3.74$ and $13.49 \pm 2.97$ $(p=0.996)$, and in the comparison values were $12.49 \pm$ 3.48 and $13.31 \pm 3.20(p=0.117)$, respectively. INT values in the intervention group were $14.93 \pm 2.42$ and $16.73 \pm 1.53(p<0.001)$, and in the comparison group values were $13.98 \pm 2.59$ and $12.89 \pm 1.93(p=0.027)$, respectively. GDS values in the intervention group were $10.09 \pm 4.06$ and $10.05 \pm 4.36(p=0.290)$, and in the comparison group values were $10.98 \pm 4.51$ and $8.69 \pm$ $4.02(p<0.001)$, respectively. SS values in the intervention group were $32.18 \pm 6.95$ and $45.22 \pm 8.94(p<0.001)$, and in the comparison group values were $35.60 \pm 6.38$ and $36.87 \pm 6.05(p<0.001)$, respectively. REL values in the intervention group were $47.95 \pm 4.94$ and $50.33 \pm 3.99$ $(p<0.001)$, and in the comparison group values were $43.38 \pm 5.71$, and $46.36 \pm 8.16(p<0.001)$, respectively. $\mathrm{PHC}$ values in the intervention group were $29.29 \pm 4.89$ and $32.82 \pm 4.27(p<0.001)$, and in the comparison group values were $26.67 \pm 5.69$ and $28.56 \pm 5.36(p<0.001)$, respectively. All values are shown in Table 2 .

The effects of intervention among older adults using linear mixed model analysis with unadjusted variables indicated that overall QOL among older adults significantly increased at both follow-ups. With each facet, physical activity and INT facets significantly increased at both follow-ups. The SOP facet significantly increased at the second follow-up, but without significance at the first follow-up. However, AUT facet significantly increased at first follow-up, but without significance at second followup. Only SAB and DAD facets did not significantly differ at both follow-ups, as shown in Table 3. However, depression trend reduced at both follow-ups, without significance. Nevertheless, PHC, SS, and REL significantly increased at both follow-ups, as shown in Table 4 .

After adjusting the variables, only SOP and PHC were statistically significant at first follow-up. At the second follow-up, overall QOL increased and with statistical significance. When dividing QOL in six facets, SAB, SOP, physical ability, and INT increased with statistical significance. Therefore, AUT and DAD facets increased at the second follow-up, but without statistical significance. The effect of intervention on depression was without statistical significance at the first follow-up, but was significant at the second follow-up as shown in Table 3. SOP of respondents increased at both follow-ups with statistical significance similar to PHC. Only REL was without statistical significance in both follow-ups; therefore, estimated mean change increased as shown in Table 3.

\section{Discussion}

The findings of this study after the intervention based on the theory of planned behavior and social network concept showed the scores for QOL (SAB, SOP, PPF, and INT components), SS, and PHC by family members increased 
Table 2 Outcome of Aging Family Network Program at Each Follow-Up

\begin{tabular}{|c|c|c|c|c|}
\hline \multirow[t]{2}{*}{ Variables } & \multicolumn{4}{|c|}{ Outcomes } \\
\hline & Baseline & Follow-Up I & Follow-Up 2 & p-value \\
\hline \multicolumn{5}{|l|}{ Intervention group } \\
\hline Quality of life (QOL) & $78.20 \pm 9.86$ & $81.65 \pm 9.35$ & $85.62 \pm 7.66$ & $<0.001 *$ \\
\hline Sensory Ability (SAB) & $11.76 \pm 3.56$ & $12.38 \pm 4.80$ & $12.67 \pm 3.07$ & 0.448 \\
\hline Autonomy (AUT) & $13.33 \pm 2.27$ & $13.47 \pm 2.16$ & $13.89 \pm 2.00$ & 0.151 \\
\hline Past-Present-Future Activity (PPF) & $12.65 \pm 2.53$ & $13.49 \pm 2.32$ & $14.25 \pm 2.00$ & $<0.001 *$ \\
\hline Social participation SOP & $13.24 \pm 2.20$ & $13.80 \pm 2.05$ & $14.56 \pm 1.87$ & $0.003 *$ \\
\hline Death \& Dying (DAD) & $13.44 \pm 3.76$ & $13.49 \pm 3.74$ & $13.49 \pm 2.97$ & 0.996 \\
\hline Intimacy (INT) & $|3.78 \pm 2.7|$ & $14.93 \pm 2.42$ & $16.73 \pm 1.53$ & $<0.001 *$ \\
\hline Geriatric Depression GDS & $11.20 \pm 4.40$ & $10.09 \pm 4.06$ & $10.05 \pm 4.36$ & 0.290 \\
\hline Social Support (SS) & $34.11 \pm 6.95$ & $32.18 \pm 6.95$ & $45.22 \pm 8.94$ & $<0.001 *$ \\
\hline Family Relationship (REL) & $42.29 \pm 6.12$ & $47.95 \pm 4.94$ & $50.33 \pm 3.99$ & $<0.001 *$ \\
\hline Perception of Health Care (PHC) & $24.15 \pm 5.36$ & $29.29 \pm 4.89$ & $32.82 \pm 4.27$ & $<0.001 *$ \\
\hline \multicolumn{5}{|l|}{ Comparison group } \\
\hline Quality of life (QOL) & $75.06 \pm 9.49$ & $77.57 \pm 12.11$ & $76.13 \pm 9.18$ & 0.330 \\
\hline Sensory ability (SAB) & $11.15 \pm 3.00$ & $11.20 \pm 2.97$ & $11.33 \pm 2.84$ & 0.895 \\
\hline Autonomy (AUT) & $12.78 \pm 2.04$ & $12.78 \pm 2.04$ & $12.87 \pm 2.16$ & 0.958 \\
\hline Past-Present-Future Activity (PPF) & $|2.7| \pm 2.32$ & $13.22 \pm 2.18$ & $12.78 \pm 2.18$ & 0.308 \\
\hline Social participation (SOP) & $12.21 \pm 2.18$ & $12.70 \pm 2.30$ & $12.95 \pm 2.47$ & 0.184 \\
\hline Death \& Dying (DAD) & $12.15 \pm 3.30$ & $12.49 \pm 3.48$ & $13.31 \pm 3.20$ & 0.177 \\
\hline Intimacy (INT) & $13.89 \pm 2.69$ & $13.98 \pm 2.59$ & $12.89 \pm 1.93$ & $0.027^{*}$ \\
\hline Geriatric Depression (GDS) & $11.65 \pm 4.46$ & $10.98 \pm 4.51$ & $8.69 \pm 4.02$ & $0.001 *$ \\
\hline Social Support (SS) & $40.15 \pm 5.99$ & $35.60 \pm 6.38$ & $36.87 \pm 6.05$ & $0.001 *$ \\
\hline Family Relationship (REL) & $41.24 \pm 5.82$ & $43.38 \pm 5.71$ & $46.36 \pm 8.16$ & $0.001 *$ \\
\hline Perception of Health Care (PHC) & $24.82 \pm 6.16$ & $26.67 \pm 5.69$ & $28.56 \pm 5.36$ & $0.001 *$ \\
\hline
\end{tabular}

Note: *p-value $<0.05$

significantly and while depression (GDS) decreased significantly in the intervention group. Furthermore, these scores differed significantly in the comparison group. Our study indicated that overall QOL improved after implementation, but only long-term effects were statistically significant. The results of this study can explain that developing the QOL among older adults takes a long time and involves many factors. The SAB, SOP, PPF, and INT of the QOL facets improved after implementing the program at the second follow-up; however, no significant improvement was found at the first follow-up. GallardoPeralta et $\mathrm{al}^{31}$ stated that family networks and social relationships are associated with quality of life in older adults. Previous studies also asserted the support from families, such as spouse or partner, ${ }^{32}$ grandchildren, ${ }^{33}$ children, ${ }^{34}$ and other related families. ${ }^{31}$ In line with Suwannarat, Panyasai ${ }^{35}$ implemented the effectiveness model participation health promotion to improve QOL for older adults in Thailand; their results revealed that the total QOL scores and subdomain QOL (eg, physical, psychological, social relationships and environment domain) were significantly improved after received intervention following a 12-week. In addition, numerous studies found that the community program can improve QOL in community-dwelling older adults compared to the usual care group. ${ }^{36,37}$

Unsurprisingly, our finding revealed that QOL in SOP, physical function and INT increased. It may have involved the activities with their family members and peers. ${ }^{17} \mathrm{SAB}$ constituted the ability to use sensory details in daily life. ${ }^{38}$ Sensory impairment commonly occurs among older adults, 
Table 3 Effects of the Intervention at Follow-Ups I and II Using Linear Mixed Model Analysis with Unadjusted Values

\begin{tabular}{|c|c|c|c|c|c|c|}
\hline \multirow[t]{2}{*}{ Outcomes } & \multicolumn{3}{|c|}{ Follow-Up I } & \multicolumn{3}{|c|}{ Follow-Up II } \\
\hline & EMC & $95 \% \mathrm{Cl}$ & p-value & EMC & $95 \% \mathrm{Cl}$ & p-value \\
\hline QOL & 4.37 & $0.233-8.5 I$ & $0.039 *$ & $|3.6|$ & $5.80-21.44$ & $0.001 *$ \\
\hline$S A B$ & 1.18 & $-0.65-3.01$ & 0.204 & 1.64 & $-1.07-4.34$ & 0.233 \\
\hline AUT & 0.29 & $0.05-0.53$ & $0.016^{*}$ & 1.04 & $-0.98-3.05$ & 0.311 \\
\hline SOP & 0.66 & $-|.09-2.4|$ & 0.457 & 1.95 & $0.21-3.68$ & $0.029 *$ \\
\hline PPF & 1.16 & $0.41-1.91$ & $0.003^{*}$ & 3.13 & $1.28-4.97$ & $0.001 *$ \\
\hline DAD & -0.24 & $-3.22-2.75$ & 0.876 & -1.06 & $-3.88-1.77$ & 0.461 \\
\hline INT & 2.20 & $0.24-4.16$ & $0.028^{*}$ & 6.89 & $4.8 \mathrm{I}-8.97$ & $<0.001 *$ \\
\hline GDS & -1.55 & $-4.80-1.7 \mid$ & 0.349 & 0.67 & $-3.16-4.51$ & 0.729 \\
\hline $\mathrm{PHC}$ & 8.44 & $6.82-10.05$ & $<0.001 *$ & 13.60 & $11.75-15.45$ & $<0.001 *$ \\
\hline SS & 8.65 & $6.91-10.40$ & $<0.001 *$ & 17.53 & $13.19-2 \mid .87$ & $<0.001 *$ \\
\hline REL & 9.16 & $7.28-11.05$ & $<0.00 I^{*}$ & 10.95 & $7.50-14.40$ & $<0.001 *$ \\
\hline
\end{tabular}

Note: *p-value $<0.05$.

Abbreviations: QOL, quality of life; SAB, sensory ability; AUT, autonomy; SOP, social participation; PPF, past-present-future activity; DAD, death \& dying; INT, intimacy; GDS, geriatric depression; REL, family relationship; SS, social support; PHC, Perception of Health Care.

Table 4 Effects of the Intervention at Follow-Ups I and II Using Linear Mixed Model Analysis with Adjusted Values

\begin{tabular}{|l|c|c|c|c|c|c|}
\hline \multirow{2}{*}{ Outcomes } & \multicolumn{3}{|c|}{ Follow-Up I } & \multicolumn{3}{c|}{ Follow-Up II } \\
\cline { 2 - 7 } & EMC & $95 \%$ Cl & p-value & EMC & $95 \%$ CI & p-value \\
\hline QOL & 11.30 & $-4.68-27.27$ & 0.164 & 67.88 & $39.05-96.70$ & $<0.00 I^{*}$ \\
SAB & 5.08 & $-2.11-12.26$ & 0.164 & 17.87 & $7.74-28.01$ & $0.00 I^{*}$ \\
AUT & 0.64 & $-0.27-1.55$ & 0.166 & 0.61 & $-7.31-8.53$ & 0.879 \\
SOP & 2.72 & $-4.54-9.98$ & 0.459 & 9.13 & $2.45-15.78$ & $0.008^{*}$ \\
PPF & 1.80 & $-1.08-4.68$ & 0.217 & 15.92 & $9.14-22.70$ & $<0.00 I^{*}$ \\
DAD & -0.93 & $-12.52-10.67$ & 0.875 & -2.23 & $-13.17-8.71$ & 0.687 \\
INT & 2.65 & $-4.98-10.28$ & 0.492 & 26.49 & $19.31-33.67$ & $<0.001 *$ \\
\hline GDS & -1.31 & $-13.99-11.37$ & 0.838 & 23.26 & $8.97-37.54$ & $0.002^{*}$ \\
\hline SS & 11.66 & $5.05-18.27$ & $0.001 *$ & 21.85 & $4.70-38.99$ & $0.013^{*}$ \\
\hline REL & 3.18 & $-4.09-10.45$ & 0.387 & 5.24 & $-8.32-18.80$ & 0.445 \\
\hline PHC & 7.75 & $1.50-13.99$ & $0.016 *$ & 14.91 & $8.08-21.73$ & $<0.00 I^{*}$ \\
\hline
\end{tabular}

Note: *p-value $<0.05$.

Abbreviations: QOL, quality of life; SAB, sensory ability; AUT, autonomy; SOP, social participation; PPF, past-present-future activity; DAD, death \& dying; INT, intimacy; GDS, geriatric depression; REL, family relationship; SS, social support; PHC, perception of health care.

such as hearing loss and visual impairment. ${ }^{39}$ Those impairments may be resolved by using hearing aids or eyeglasses. One limitation of this research was the lack of information regarding sensory impairment. Thus, improved sensory ability facets remain unclear. Related studies have illustrated that this was associated with sensory aids and treatments, supported by family members and health organizations. ${ }^{38}$ However, AUY, and DAD facets did not improve significantly after implementing the intervention. This was because the QOL scores among older adults were already high before participating in the intervention.

Lack of self-care behaviors and presence of depression are common among older adults. ${ }^{11,40,41}$ Our study found that depression was prevalent before the intervention. After the intervention, depression was reduced at both follow-ups. People who participate with friends or peers in social organizations or clubs tend to have fewer 
depressive symptoms, particularly in older adults. ${ }^{42}$ In addition, our results revealed that the intervention could reduce depression, similar to increasing QOL. Self-care management, depression, and QOL have reciprocal causations and exacerbate one another. ${ }^{37,43}$ Markle-Reid et al ${ }^{37}$ implemented the community program in older adults; their results revealed that the community program from interdisciplinary team including families and caregivers significantly reduced depressive symptoms and improved selfmanagement in community-dwelling older adults compared to control group. ${ }^{37}$

Our findings demonstrated that social support by family member improved after the intervention at the 9th and 12th months follow-ups. Numerous studies asserted that social support is a significant predictor directly associated with mental and physical well-being in older adults. ${ }^{44,45}$ Cattan et al ${ }^{46}$ reviewed thirty intervention studies and also included group-oriented educational programs in older adults; their results asserted that the intervention can improve social support in older adults in the intervention group compared to the control group.

Additionally, perceptions of health care by family member improved after the intervention at both followups. Perception of health considered is an essential predictor to improve older adults' well-being and it is a predictor of readmission rate and mortality regarding the clinical health status. ${ }^{47}$ Previous study has shown that older age is associated with poor health status, which in turn leads to poor outcomes. ${ }^{48,49}$ This study improved knowledge level, attitudes and behaviors of family members, and may have caused older adults to receive more care from their family members. For this reason, PHC improved among older adults in the intervention group. However, our study found no statistical significance in family support for older adults in rural community.

For this study's implications, the effects of this program were partly able to improve overall QOL, sensory ability, social participation, intimacy, social support, and perception of health care from family members as well as decreased depression scores in older adults. Further studies should be conducted to test and confirm the effect of older family network programs in order to improve QOL and health outcomes among older adults with larger sample sizes.

This study encountered several limitations. First, it only measured outcomes after completing the program, making the sustained effects of this program uncertain. The impact of health care such as health condition was not assessed. This study did not assess the value of the program; for this reason, the cost-effectiveness of the intervention should be assessed for policy decisions. Secondly, this study's findings could not be generalized to a wider aging population because the sample excluded subjects who were frail or bedbound and those with cognitive impairment and dementia. Further, subjects residing alone or with vulnerable people, such as adults with AIDS or mental disorders, were not included. Third, the study employed a small sample size; thus, our results may not be generalizable to the entire older adult population. Fourth, we used convenience sampling; the lack of random sampling may contribute to sample selection bias and limit the findings' generalization. Fifth, we assessed socioeconomic data, PHC, family support, family relationship, depression and QOL with only a self-reported questionnaire. Lastly, this study may only be appropriate for community dwelling older adults. There may be various factors affecting the program implementation in urban and industrial communities, such as fewer social ties and less social cohesion than those found in rural communities. By exploring these differences, future studies may explore the social ties and true success of the intervention.

\section{Conclusion}

To the best of our knowledge, our study asserted that health promotion using family members can improve social support and perception of health care from family members, and reduce depression long term for older adults in rural community. Our study also found that the older family network program can improve the overall QOL as well as sensory ability, social participation, and intimacy components of the QOL. Based on the results of this study, healthcare providers and policymakers should implement intervention to improve quality of life among older adults. Interventions are needed to ensure improved QOL and health outcomes in older adults, which is important for aging society in Thailand.

\section{Abbreviations}

QOL, quality of life; SAB, sensory ability; AUT, autonomy; SOP, social participation; PPF, past-present-future activity; DAD, death \& dying; INT, intimacy; GDS, geriatric depression score; REL, family relationship; SS, social support; PHC, perception of health care.

\section{Data Sharing Statement}

The datasets generated during and/or analyzed during the current study are available from the corresponding author on reasonable request. 


\section{Acknowledgment}

We would like to thank the participants in our work for their valuable data, the reviewers for their helpful comments and suggestions to improve our study.

\section{Author Contributions}

All authors made a significant contribution to the work reported, whether that is in the conception, study design, execution, acquisition of data, analysis and interpretation, or in all these areas; took part in drafting, revising or critically reviewing the article; gave final approval of the version to be published; have agreed on the journal to which the article has been submitted; and agree to be accountable for all aspects of the work.

\section{Funding}

The current study was supported by the Thailand Research Fund (TRF) [grant number MRG 6080217].

\section{Disclosure}

The authors of this study declare that they have no conflicts of interest in this work.

\section{References}

1. Zueras P, Rentería E, Devleesschauwer B. Trends in disease-free life expectancy at age 65 in Spain: diverging patterns by sex, region and disease. PLoS One. 2020;15(11):e0240923. doi:10.1371/journal. pone. 0240923

2. Suksatan W, Ounprasertsuk J. Health-promoting behaviors and related factors in patients with chronic diseases in a rural community. Syst Rev Pharm. 2020;11(10):624-627. doi:10.31838/srp.2020.10.93

3. Loprinzi PD, Lee H, Cardinal BJ. Evidence to support including lifestyle light-intensity recommendations in physical activity guidelines for older adults. Am J Health Promot. 2015;29(5):277-284. doi:10.4278/ajhp.130709-QUAN-354

4. Or R, Kartal A. Influence of caregiver burden on well-being of family member caregivers of older adults. Psychogeriatrics. 2019;19 (5):482-490. doi:10.1111/psyg.12421

5. Yuan S, Hussain SA, Hales KD, Cotten SR. What do they like? Communication preferences and patterns of older adults in the United States: the role of technology. Educ Gerontol. 2016;42 (3):163-174. doi:10.1080/03601277.2015.1083392

6. LaRocca MA, Scogin FR. The effect of social support on quality of life in older adults receiving cognitive behavioral therapy. Clin Gerontol. 2015;38(2):131-148. doi:10.1080/07317115.2014.990598

7. Hasanpour-Dehkordi A, Khaledi-Far A, Khaledi-Far B, Salehi-Tali S. The effect of family training and support on the quality of life and cost of hospital readmissions in congestive heart failure patients in Iran. Appl Nurs Res. 2016;31:165-169. doi:10.1016/j.apnr.2016.03.005

8. Lu C, Yuan L, Lin W, Zhou Y, Pan S. Depression and resilience mediates the effect of family function on quality of life of the elderly. Arch Gerontol Geriatr. 2017;71:34-42. doi:10.1016/j.archger. 2017.02.011
9. Kurpas D, Mroczek B, Bielska D. The correlation between quality of life, acceptance of illness and health behaviors of advanced age patients. Arch Gerontol Geriatr. 2013;56(3):448-456. doi:10.1016/j. archger.2012.12.010

10. Crimmins EM, Zhang YS. Aging populations, mortality, and life expectancy. Annu Rev Sociol. 2019;45(1):69-89. doi:10.1146/ annurev-soc-073117-041351

11. Suksatan W, Tankumpuan T. Depression and rehospitalization in patients with heart failure after discharge from hospital to home: an integrative review. Home Health Care Manag Pract. 2021;108482232098696. doi:10.1177/1084822320986965

12. Merluzzi TV, Philip EJ, Vachon DO, Heitzmann CA. Assessment of self-efficacy for caregiving: the critical role of self-care in caregiver stress and burden. Palliat Support Care. 2011;9(1):15. doi:10.1017/ S1478951510000507

13. Borhaninejad V, Iranpour A, Shati M, Tahami AN, Yousefzadeh G, Fadayevatan R. Predictors of self-care among the elderly with diabetes type 2: using social cognitive theory. Diabetes Metab Syndr. 2017;11(3):163-166. doi:10.1016/j.dsx.2016.08.017

14. Rivera-Hernandez M. Depression, self-esteem, diabetes care and self-care behaviors among middle-aged and older Mexicans. Diabetes Res Clin Pract. 2014;105(1):70-78. doi:10.1016/j. diabres.2014.04.017

15. Vellone E, Fida R, D'Agostino F, et al. Self-care confidence may be the key: a cross-sectional study on the association between cognition and self-care behaviors in adults with heart failure. Int J Nurs Stud. 2015;52(11):1705-1713. doi:10.1016/j.ijnurstu. 2015.06.013

16. Rivera E, Corte C, Steffen A, DeVon HA, Collins EG, McCabe PJ. Illness representation and self-care ability in older adults with chronic disease. Geriatrics. 2018;3(3):45. doi:10.3390/geriatrics3030045

17. Shahriari M, Ahmadi M, Babaee S, Mehrabi T, Sadeghi M. Effects of a family support program on self-care behaviors in patients with congestive heart failure. Iran J Nurs Midwifery Res. 2013;18 (2):152-157.

18. Ringer T, Hazzan AA, Agarwal A, Mutsaers A, Papaioannou A. Relationship between family caregiver burden and physical frailty in older adults without dementia: a systematic review. Syst Rev. 2017;6(1):55. doi:10.1186/s13643-017-0447-1

19. Conner M. Theory of planned behavior. In: Handbook of Sport Psychology. 2020:1-18.

20. Ajzen I. The theory of planned behavior. Organ Behav Hum Decis Process. 1991;50(2):179-211. doi:10.1016/0749-5978(91)90020-T

21. Sniehotta FF, Presseau J, Araújo-Soares V. Time to retire the theory of planned behaviour. Health Psychol Rev. 2014;8(1):1-7. doi:10.1080/17437199.2013.869710

22. Kaewmoon P, Nanthamongkolchai S, Munsawaengsub C, Pitikultang S, Yodmai K. Health promotion program with family participation among uncontrolled type 2 diabetic elderly. Thai $J$ Health Educ. 2020;43(2):119-133.

23. Siridamrongchai L, Nanthamongkolchai S, Munsawaengsub C, Thechaboonsermsak $\mathrm{P}$, Yodmai K. Health promotion program to elderly with hypertension by family participation. J Public Health. 2018;48(2):161-173.

24. Cobb S. Social support as a moderator of life stress. Psychosom Med. 1976;38:300-314. doi:10.1097/00006842-197609000-00003

25. Yesavage JA, Brink TL, Rose TL, et al. Development and validation of a geriatric depression screening scale: a preliminary report. J Psychiatr Res. 1982;17(1):37-49. doi:10.1016/0022-3956(82)90033-4

26. Brain Rehabilitation Group. Model for measuring sadness in the elderly in Thailand. Sarn Siriraj. 1994;19.

27. Power M, Quinn K, Schmidt S, Group WO. Development of the WHOQOL-old module. Qual Life Res. 2005;14(10):2197-2214. doi:10.1007/s11136-005-7380-9 
28. Somrongthong R, Wongchalee S, Ramakrishnan C, Hongthong D, Yodmai K, Wongtongkam N. Influence of socioeconomic factors on daily life activities and quality of life of Thai elderly. J Public Health Res. 2017;6(1):862. doi:10.4081/jphr.2017.862

29. Diggle P, Diggle PJ, Heagerty P, Liang KY, Heagerty PJ, Zeger S. Analysis of Longitudinal Data. Oxford University Press; 2002.

30. Gueorguieva R, Krystal JH. Move over ANOVA: progress in analyzing repeated-measures data and Its reflection in papers published in the Archives of General Psychiatry. Arch Gen Psychiatry. 2004;61 (3):310-317. doi:10.1001/archpsyc.61.3.310

31. Gallardo-Peralta LP, de Roda ABL, Ángeles Molina- Martínez M, Schettini Del Moral R. Family and community support among older Chilean adults: the importance of heterogeneous social support sources for quality of life. J Gerontol Soc Work. 2018;61 (6):584-604. doi:10.1080/01634372.2018.1489928

32. Thomas PA. Is it better to give or to receive? Social support and the well-being of older adults. J Gerontol B Psychol Sci Soc Sci. 2010;65b(3):351-357. doi:10.1093/geronb/gbp113

33. Moorman SM, Stokes JE. Solidarity in the grandparent-adult grandchild relationship and trajectories of depressive symptoms. Gerontologist. 2016;56(3):408-420. doi:10.1093/geront/gnu056

34. Grundy E, Read S. Social contacts and receipt of help among older people in England: are there benefits of having more children? $J$ Gerontol Series B. 2012;67(6):742-754. doi:10.1093/geronb/ gbs082

35. Suwannarat J, Panyasai K. Effectiveness model of participation health promotion for quality of life among the elderly. Public Health J Burapha Univ. 2019;14(2):52-62.

36. Markle-Reid M, Ploeg J, Fraser KD, et al. The ACHRU-CPP versus usual care for older adults with type-2 diabetes and multiple chronic conditions and their family caregivers: study protocol for a randomized controlled trial. Trials. 2017;18(1):55. doi:10.1186/ s13063-017-1795-9

37. Markle-Reid M, Ploeg J, Fraser KD, et al. Community program improves quality of life and self-management in older adults with diabetes mellitus and comorbidity. J Am Geriatr Soc. 2018;66 (2):263-273. doi:10.1111/jgs.15173

38. Tseng YC, Liu SHY, Lou MF, Huang GS. Quality of life in older adults with sensory impairments: a systematic review. Qual Life Res. 2018;27(8):1957-1971. doi:10.1007/s11136-018-1799-2

39. Simning A, Fox ML, Barnett SL, Sorensen S, Conwell Y. Depressive and anxiety symptoms in older adults with auditory, vision, and dual sensory impairment. J Aging Health. 2018;31(8):1353-1375. doi: $10.1177 / 0898264318781123$
40. Son YJ, Lee K, Kim BH. Gender differences in the association between frailty, cognitive impairment, and self-care behaviors among older adults with atrial fibrillation. Int J Environ Res Public Health. 2019;16(13):2387. doi:10.3390/ijerph16132387

41. O'Conor R, Smith SG, Curtis LM, Benavente JY, Vicencio DP, Wolf MS. Mild visual impairment and its impact on self-care among older adults. $J$ Aging Health. 2016;30(3):327-341. doi:10.1177/0898264316676406

42. Donnelly EA, Hinterlong JE. Changes in social participation and volunteer activity among recently widowed older adults. Gerontologist. 2009;50(2):158-169. doi:10.1093/geront/gnp103

43. Iovino P, De Maria M, Matarese M, Vellone E, Ausili D, Riegel B. Depression and self-care in older adults with multiple chronic conditions: a multivariate analysis. J Adv Nurs. 2020;76(7):1668-1678. doi:10.1111/jan.14385

44. Tsuji K, Khan HT. Exploring the relationship between social support and life satisfaction among rural elderly in Japan. Ageing Int. 2016;41 (4):414-426. doi:10.1007/s12126-016-9254-6

45. de Guzman AB, Jurado JBN, Juson AJA. Examining the structural relationship of chronic illness, physical function, life satisfaction, and social support in the development of depression among Filipino elderly in institutionalized settings. Educ Gerontol. 2015;41 (3):193-206. doi:10.1080/03601277.2014.918836

46. Cattan M, White M, Bond J, Learmouth A. Preventing social isolation and loneliness among older people: a systematic review of health promotion interventions. Ageing Soc. 2005;25(1):41-67. doi:10.1017/ S0144686X04002594

47. Tkatch R, Musich S, MacLeod S, et al. A qualitative study to examine older adults' perceptions of health: keys to aging successfully. Geriatr Nurs. 2017;38(6):485-490. doi:10.1016/j. gerinurse.2017.02.009

48. Ounprasertsuk J, Benjanirat T, Jaroenngarmsamer P, et al. The application of geographic information system for assessing the risk leve of hypertension in Samut Songkhram Province. Syst Rev Pharm. 2020;11(10):491-497. doi:10.31838/srp.2020.10.73

49. Carreon D, Noymer A. Health-related quality of life in older adults: testing the double jeopardy hypothesis. J Aging Stud. 2011;25 (4):371-379. doi:10.1016/j.jaging.2011.01.004
Journal of Multidisciplinary Healthcare

\section{Publish your work in this journal}

The Journal of Multidisciplinary Healthcare is an international, peerreviewed open-access journal that aims to represent and publish research in healthcare areas delivered by practitioners of different disciplines. This includes studies and reviews conducted by multidisciplinary teams as well as research which evaluates the results or conduct of such teams or healthcare processes in general. The journal covers a very wide range of areas and welcomes submissions from practitioners at all levels, from all over the world. The manuscript management system is completely online and includes a very quick and fair peer-review system. Visit http://www.dovepress.com/testimonials. php to read real quotes from published authors. 